\title{
Effects of particle size on mechanical behaviors of calcareous sand under triaxial conditions
}

\author{
Pei Cao ${ }^{\text {i, ii) }}$, Ming-jing JIANG ${ }^{\text {ii iii) }}$ and Zhi-jun DING ${ }^{\text {IV) }}$ \\ i) Key Laboratory of Geotechnical and Underground Engineering of Ministry of Education, Tongji University, Shanghai 20092, China. \\ ii) Dept. of Geotechnical Engineering, Tongji University, Shanghai 200092, China. \\ iii) School of Civil Engineering, Tongji University, Shanghai 200092, China. \\ iv ) Department of Civil Engineering, University of Shanghai for Science and Technology, Shanghai 200093, China.
}

\begin{abstract}
The influence of particle size on the mechanical behavior of calcareous sand, which was obtained from the seabed in South China Sea, was studied. A series of triaxial compression tests were carried out on samples with different particle size distributions, which the maximum diameters of particles are $2 \mathrm{~mm}$ and $20 \mathrm{~mm}$ respectively. The results show that calcareous sand presents stress-strain soften behavior. The shear stress increase with particle size. With the increase of shear strain, the volumetric strain changes from contraction to dilatation. The dilatation tendency decrease with increasing particle size and effective confining pressure. Samples with coarse grains $(\leq 20 \mathrm{~mm})$ shows completely compression under high effective confining pressure $(800 \mathrm{kPa})$. The peak state friction angle and critical state friction angle were also influenced by particle size. There is unique critical state line in $p^{\prime}-q$ plane no matter particle size.
\end{abstract}

Keywords: calcareous sand, particle size, shear strength, dilatancy

\section{INTRODUCTION}

Calcareous sand, widely spread on coral reefs in Nansha Islands, South China Sea, is a kind of special geotechnical medium due to its biological composition and marine sedimentary environment. With the development of oceanic engineering, more and more attention is paid to the utilization of calcareous sand as backfill material in reclaimed land. It is the main raw material in the ocean construction. Due to the unique marine formation environment, calcareous sand is mainly composed of calcium carbonate and its contents range up to 95\% (Wang et al. 2017; Qian et al. 2017). So it is characterized by irregular shapes, high porosity and particle crush (Zhu et al. 2014; Zhang et al. 2009). It has been proved that the engineering properties of calcareous sand are more complex than the conventional geotechnical materials (Datta 1980, Coop 1990; Brandes 201; Shahnazari 2013; Wang 2019).

Particle size plays an important role on the strength and deformation behavior of calcareous sand and many other granular materials such as sand, gravels and rockfill material. To evaluate the influence of particle size, a great deal of laboratory tests as well as numerical simulating had been performed. The conclusions about the individual effect of each of these parameters were diversity. Islam et al. (2011) reported that particle size is one of the important properties which play a dominant role on the stress, strain and strength responses of granular materials. Alteration of grain size results in the change of void ratio as well as particle effective contact area revolutionized and the load distribution mechanism of particle to particle contact. Based on tests conducted on different size of granular soil samples, Dunn and Bora (1972) revealed that the shear strength increases as particle size increase. Islam et al. (2011) also observed that for normal load with the increase of particle size, angle of internal friction as well as maximum horizontal shear stress increases for uniform sands and graded sands, but the larger the gradation the higher the shear strength. Wang et al. (2013) found the angle of shearing resistance of accumulation soil is generally increasing with increasing median particle diameter and gravel content and decreasing with increasing coefficient of uniformity. Calcareous sand and silica sand show opposite responses for particle size in confined and bulk modulus (Lv 2019). Koerner (1970) and Marachi et al. (1972) found that the shear strength decreases with the increase of particle size. Vangla (2015) observed from the symmetric direct shear tests that the particle size has no effect on the peak friction angle when the tests were carried out at same void ratio, but ultimate friction angles were affected by the particle size.

The diversity of the conclusions of conducted research revealed an ambiguity which leads to further investigations. Moreover, theoretical relationships between the particle size and stress-strain and strength are still elusive.

This study aims to investigate the particle size effect 
on the shear strength parameters and deformation behaviour of calcareous sand, based on triaxial compression test for calcareous sand with different particle sizes.

\section{MATERIALS AND METHODS}

For this study, the calcareous sand was obtained from a reef of Nansha Islands in South China Sea. The calcareous sand is mainly composed of accumulation of pieces of dead madrepore and halobios corals broken by waves and currents (Wang 2014) that the main chemical composition of it is calcium carbonate. Its original grain size distribution curve is in Fig. 1. It can be seen that the maximum particle diameter can reach $200 \mathrm{~mm}$ and the content of particles larger than $2 \mathrm{~mm}$ was more than 50 percent. In order to investigate the effect of gradation, two kinds of particle gradation: G1 and G2 were prepared. The grain size distribution curves of them are shown in Fig. 1.

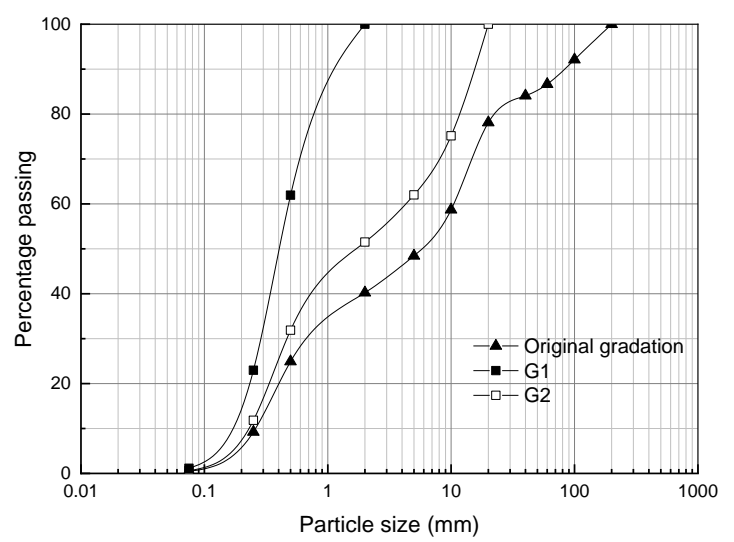

Fig. 1 Grain size distributions for calcareous sand

The two test gradations were obtained from the original gradation by scalping and replacement method. In this method, the particles which diameter larger than the maximum allowable particle diameter were deleted directly, and the gradation distribution curve is drawn in accordance with the definition of the formula (1):

$$
P_{i}=P_{o i} /\left(100-P_{d \max }\right)
$$

Here, $P_{\mathrm{i}}$ : group proportion of test gradation (\%);

$P_{\mathrm{oi}}$ : group proportion of original gradation $(\%)$;

$P_{\mathrm{dmax}}$ : group proportion of oversized particles $(\%)$.

Before the test, the calcareous sand was dried by oven and then divided into 7 particle groups by sieving: $20-10$ $\mathrm{mm}, 10-5 \mathrm{~mm}, 5-2 \mathrm{~mm}, 2-0.5 \mathrm{~mm}, 0.5-0.25 \mathrm{~mm}, 0.25-$ $0.075 \mathrm{~mm}$ and $\leqslant 0.075 \mathrm{~mm}$, and is shown in Fig.2. Then the two predetermined gradations were achieved by mixing particle groups under different group proportions. Tthe basic property parameters of them are shown in Table 1 and all the values were obtained according to the rules in the Chinese National Standard for Soil Test Method (GB50123-2019).

A series of triaxial tests were performed on the calcareous sand with two different gradations (G1 and
G2). The specimen size is $100 \mathrm{~mm}$ diameter and $200 \mathrm{~mm}$ height. All specimens were prepared by water sedimentation into a mould in five layers with necessarily vibrating to achieve the same relative density of $\mathrm{Dr}=80 \%$. The calcareous sand was very hard to be saturated for there was much inner pore in grains. In order to improve the degree of saturation, oven dried sand was first weighted and divided into five equallyweighted portions, and then submerged in distilled water for 12 hours prior to vacuum for 2 hours. After be sealed in vacuuming device under a vacuum of $100 \mathrm{kPa}$ for 12 hours, each portion of calcareous sand with distilled water was strewed into the mould with a tiny spoon. To raise the degree of saturation, a back pressure of $200 \mathrm{kPa}$ was applied to specimen through the drainage line, and the Skempton's B value could reach 0.98 or even higher.

Table 1 Basic properties of the calcareous sands used in the study

\begin{tabular}{llll}
\hline Property & $\begin{array}{l}\text { Original } \\
\text { gradation }\end{array}$ & $\mathrm{G} 1$ & $\mathrm{G} 2$ \\
\hline$d_{10}(\mathrm{~mm})$ & 0.27 & 0.14 & 0.22 \\
\hline$d_{30}(\mathrm{~mm})$ & 0.75 & 0.30 & 0.48 \\
\hline$d_{50}(\mathrm{~mm})$ & 5.80 & 0.40 & 1.85 \\
\hline$d_{60}(\mathrm{~mm})$ & 11.5 & 0.48 & 4.35 \\
\hline Uniformity coefficient $C_{\mathrm{u}}$ & 42.59 & 3.43 & 19.77 \\
\hline Coefficient of curvature $C_{\mathrm{c}}$ & 0.181 & 1.34 & 0.24 \\
\hline Maximum void ratio $e_{\max }$ & $/$ & 1.376 & 1.135 \\
\hline Minimum void ratio $e_{\min }$ & $/$ & 0.986 & 0.758 \\
\hline
\end{tabular}

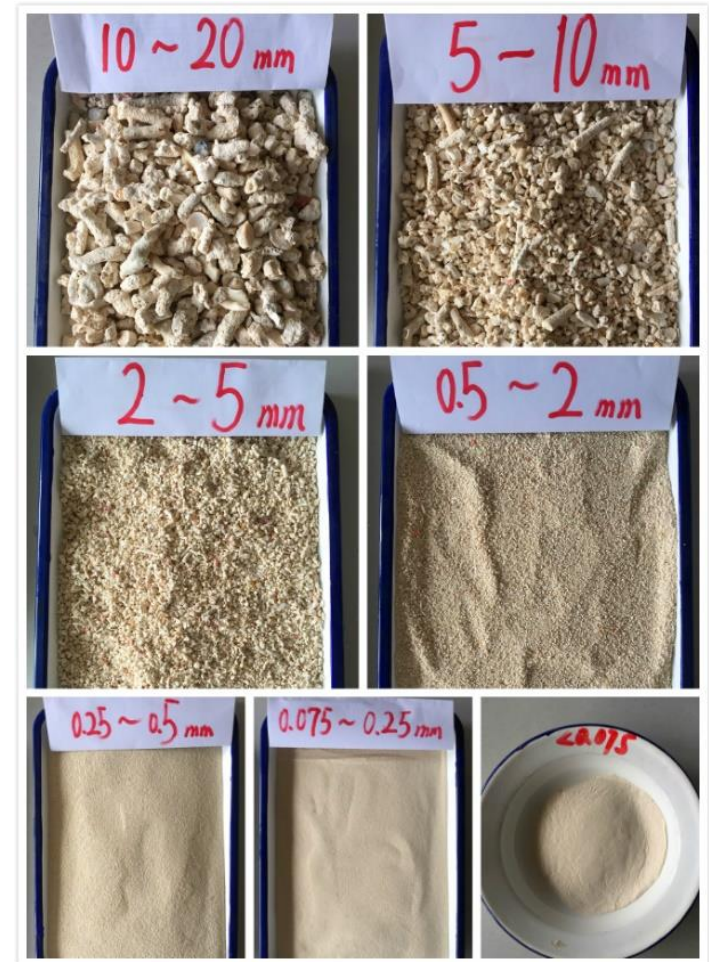

Fig. 2 Different grain sizes used in preparing gradations

After reaching saturation, the specimen was subjected to the predetermined effective confining pressure $(50 \mathrm{kPa}, 100 \mathrm{kPa}, 200 \mathrm{kPa}, 400 \mathrm{kPa}$ and 800 $\mathrm{kPa}$ ). Then the sample was sheared under the drained condition with a constant axial strain rate of $0.05 \% / \mathrm{min}$. 
The test was stopped when the accumulated axial strain reached $30 \%$. Based on the test results, the volumetric strain and stress changed only slightly at an axial strain of $30 \%$. According to the definition of the critical state, it can be regarded that sample reached the critical state at this axial strain.

\section{TEST RESULTS}

\subsection{Stress-strain relationships}

Fig. 3 show stress-strain curves and the related volumetric strain-axial strain curves of calcareous sand specimens under different confining pressure. In Fig.3, the volumetric strain $\varepsilon_{\mathrm{v}}$ is positive for compression and negative for dilatation. It is clearly shown that, the stressstrain curves for calcareous sand with different gradation are of softening type, in which the stress continuously increases with the axial strain and then decreases towards an ultimate state. Both the peak strength and residual strength increase with increasing effective confining pressure.

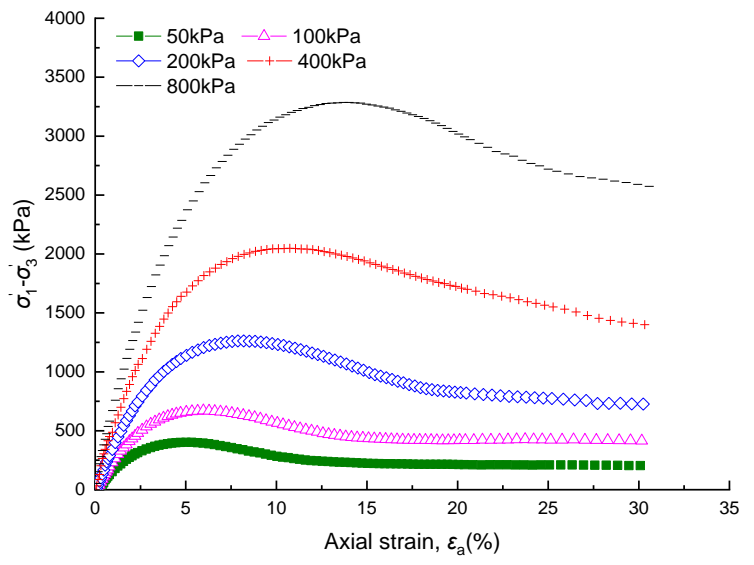

(a) $\left(\sigma_{1}^{\prime}-\sigma_{3}^{\prime}\right) \sim \varepsilon_{a}$ of Sample G1

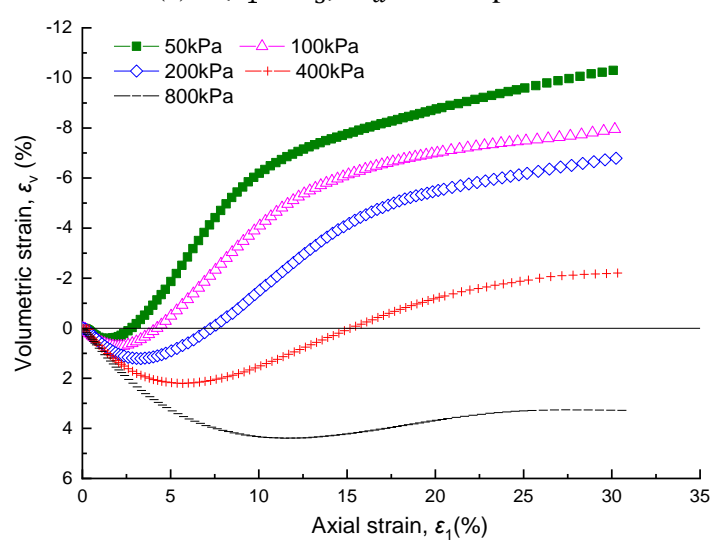

(b) $\varepsilon_{v} \sim \varepsilon_{a}$ of Sample G1

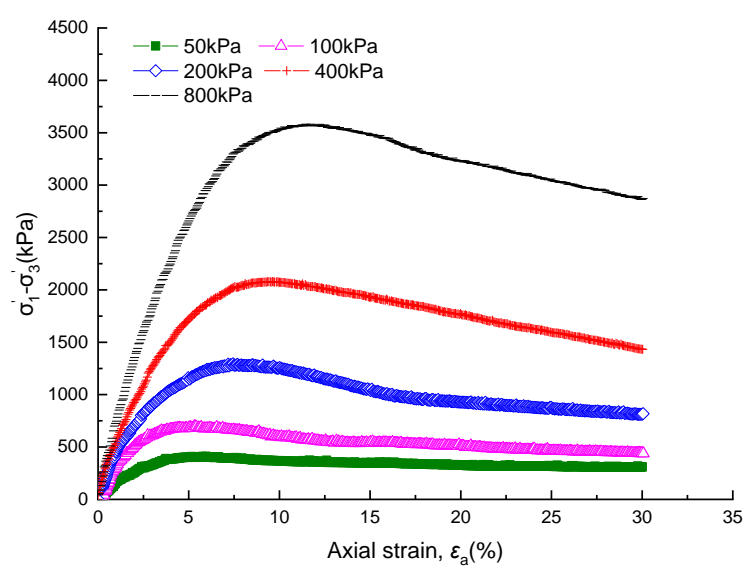

(c) $\left(\sigma_{1}^{\prime}-\sigma_{3}^{\prime}\right) \sim \varepsilon_{a}$ of Sample G2

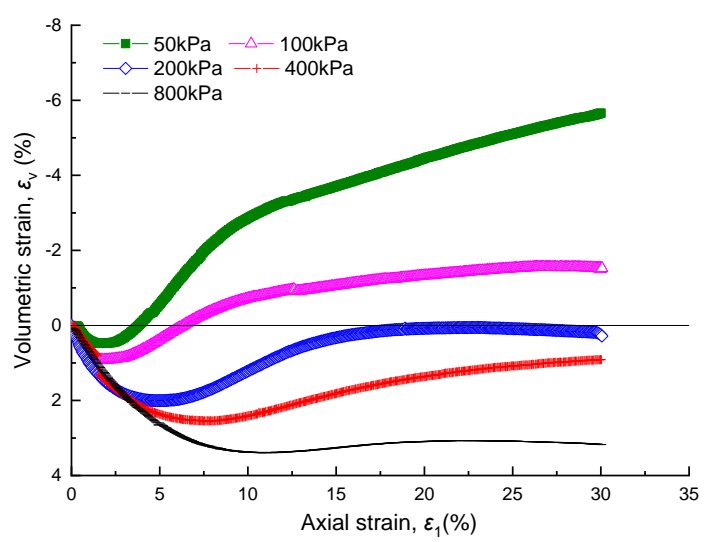

(d) $\varepsilon_{v} \sim \varepsilon_{a}$ of Sample G2

Fig. 3 Test results.

It also shows that the volumetric strain presents contract during the early stage of shear, and then, it subsequently dilates. With increasing confining pressure, the amount and process of contraction increase and the dilatation decreases. The primary form of deformation of calcareous sand is dilatation for an effective confining pressure of $50 \mathrm{kPa}$, but it is contraction for an effective confining pressure of $800 \mathrm{kPa}$.

The shear dilation of sample G2 is much lower than the shear dilation of Sample G1 with the same effective confining pressure. Furthermore, sample G1 presents dilatation in general when the effective confining pressure less than $400 \mathrm{kPa}$. However, $200 \mathrm{kPa}$ is the division between dilatation and compression of large sample. The distinction between the two kinds of samples of calcareous sand on volumetric development can be explained by their gradation. Sample G2 has more larger size particles, and the grain breakage appears more easily in Sample G2 than in Sample G1 with the same effective confining pressure. The particle breakage will modify the structure of test sample, and influence the dilatation.

\subsection{Shear strength}

It is widely accepted that the mobilized strengths of soil can reflect the progressive soil behavior during shearing. According to the critical state soil mechanism, 
the mobilized friction angle $\varphi \_m$ under the triaxial compression condition can be defined as:

$$
\sin \varphi_{m}=3 \eta /(6+\eta)
$$

The stress ratio $\eta$ here is defined as the ratio of the deviatoric stress $q$ to the mean effective normal stress $p^{\prime}$ :

$$
\begin{gathered}
\eta=\mathrm{q} / \mathrm{p}^{\prime} \\
\mathrm{p}^{\prime}=\left(\sigma_{1}^{\prime}+\sigma_{2}^{\prime}+\sigma_{3}^{\prime}\right) / 3 \\
\mathrm{q}=\sigma_{1}^{\prime}+\sigma_{2}^{\prime}
\end{gathered}
$$

where $\sigma_{1}^{\prime}, \sigma_{2}^{\prime}$ and $\sigma_{3}^{\prime}$ are major, intermediate, and minor effective principal stresses, respectively.

The peak state friction angle $\varphi_{p s}$ and critical state friction angle $\varphi_{c s}$ under the triaxial compression condition can be defined as:

$$
\begin{gathered}
\sin \varphi_{p s}=3 \eta_{p s} /\left(6+\eta_{p s}\right) \\
\sin \varphi_{c s}=3 \eta_{c s} /\left(6+\eta_{c s}\right)
\end{gathered}
$$

where $\eta_{\mathrm{ps}}$ and $\eta_{\mathrm{cs}}$ are the peak state stress ratio and critical state stress ratio, respectively.

Fig. 4 shows the effective mean normal stress $p$ ' versus the deviatoric stress $q$, measured at the peak state and critical state respectively. It can be seen that in $p^{\prime}-q$ plane, the relationships between effective mean normal stress and deviatoric stress at both the peak state and critical state are basically a straight line passing through the origin. The particle size has no effect on the uniqueness of peak state line and critical state line in $p^{\prime}-$ $q$ plane.

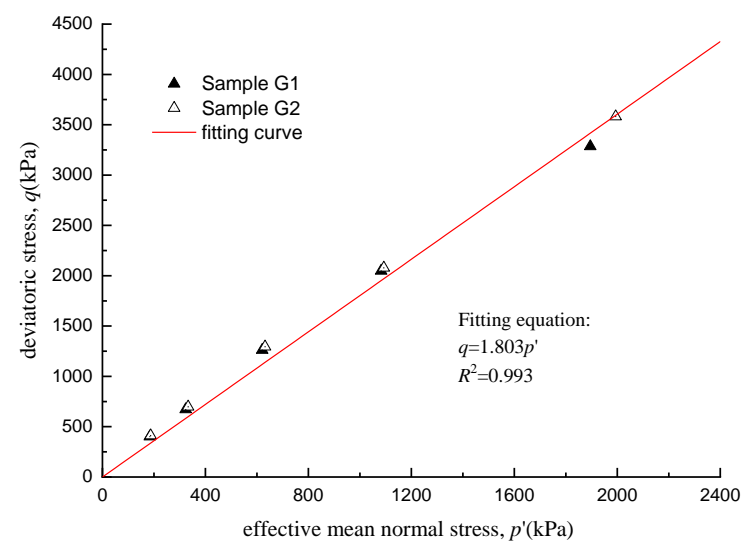

(a) peak state

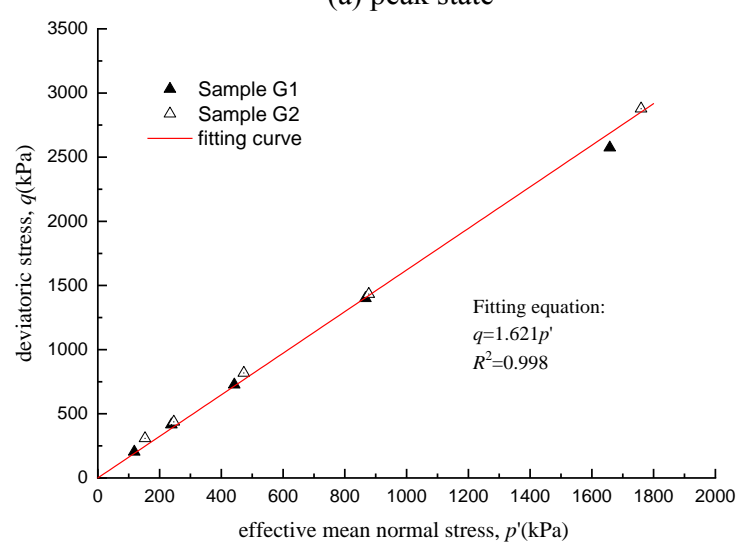

(b) critical state

Fig.4 Relationship between deviation stress and effective mean normal stress
Fig.5 presents the values of the peak state friction angle $\varphi_{\mathrm{ps}}$ and critical state friction angle $\varphi_{\mathrm{cs}}$ of the two kinds of samples at different initial effective mean normal pressure. It can be seen that the initial effective mean normal pressure $\mathrm{p}_{0}$ ' has a clearly influence on both the peak state friction angle $\varphi_{\mathrm{ps}}$ as well as the critical state friction angle $\varphi_{\text {cs }}$. The effects of particle size on the peak state friction angle and critical state friction angle are very little. The relationships between the friction angle and initial effective mean normal pressure can be expressed as

$$
\begin{gathered}
\varphi_{p s}=\varphi_{p s 0}-\Delta \varphi_{p s} \lg \left(p_{0}^{\prime} / p_{a}\right) \\
\varphi_{c s}=\varphi_{c s 0}-\Delta \varphi_{c s} \lg \left(p_{0}^{\prime} / p_{a}\right)
\end{gathered}
$$

Where $p_{0}^{\prime}$ is the initial effective mean normal stress; $p_{a}$ is the atmospheric pressure; $\varphi_{p s 0}, \Delta \varphi_{p s}, \varphi_{c s 0}$, $\Delta \varphi_{c s}$ are material constants, here $\varphi_{p s 0}=51.35^{\circ}$, $\Delta \varphi_{p s}=8.13^{\circ}, \varphi_{c s 0}=44.40^{\circ}, \Delta \varphi_{c s}=5.55^{\circ}$.

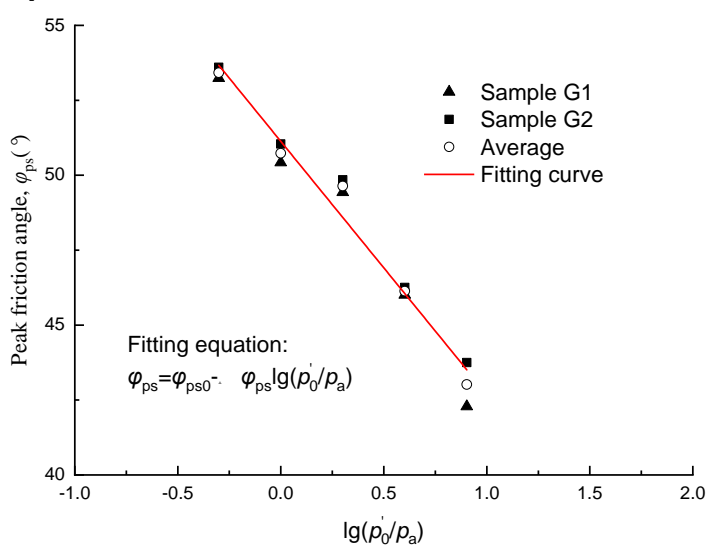

(a) peak state friction angle

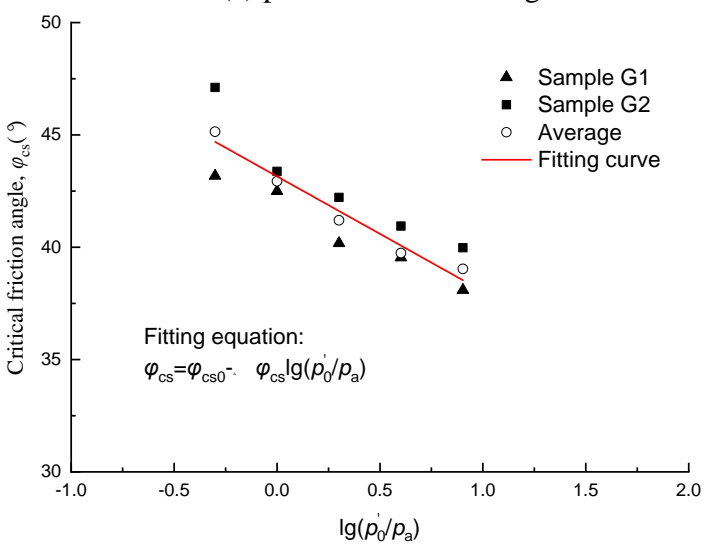

(b) critical state friction angle

Fig. 5 Variation in critical state friction angle with initial effective mean normal stress

\subsection{Shear Dilatancy}

The dilatancy $d$ is defined as the ration of plastic volumetric strain increment to the plastic main principal strain increment in triaxial space (Bolton 1986). The dilatancy point is the transition point at which a transformation from shear contraction to shear dilatancy of the sample's volume deformation occurs.

Based on the observation of the dilative shear 
behavior of sand, Li and Dafalias (2000) proposed a state-dependent dilatancy function as follows:

$$
d=d_{1}\left(e^{m \psi}-\eta / M\right)
$$

where $e$ is the current void ratio; $d_{1}$ and $\mathrm{m}$ are two model costants; $M$ is the critical stress ratio; $\psi$ is the state parameter can be expressed as (Been and Jefferies 1985, $\mathrm{Li}$ and Wang 1998):

$$
\psi=e-e_{c}=e-\left[e_{\Gamma}-\lambda_{c}\left(p^{\prime} / p_{a}\right)^{\xi}\right]
$$

where $e_{\Gamma}$ and $\lambda_{\mathrm{c}}$ are the critical void ratio intercepting and the slope of critical line in $e-\left(p^{\prime} / p_{a}\right)^{\xi}$ plane, respectively; $\xi$ is chosen 0.68 here.

Fig. 6 shows the critical state line (CSL) of calcareous sand in $e-\left(p^{\prime} / p_{a}\right)^{\xi}$ plane obtained from drained triaxial compression tests. It can be seen that the CSL of sample G1 is different from CSL of sample G2. Particle size has clearly influence on CSL in $e-$ $\left(p^{\prime} / p_{a}\right)^{\xi}$ plane. But as shown in Fig. 4 , there is a unique CSL for the two kinds of sample in $p^{\prime}-q$ plane.

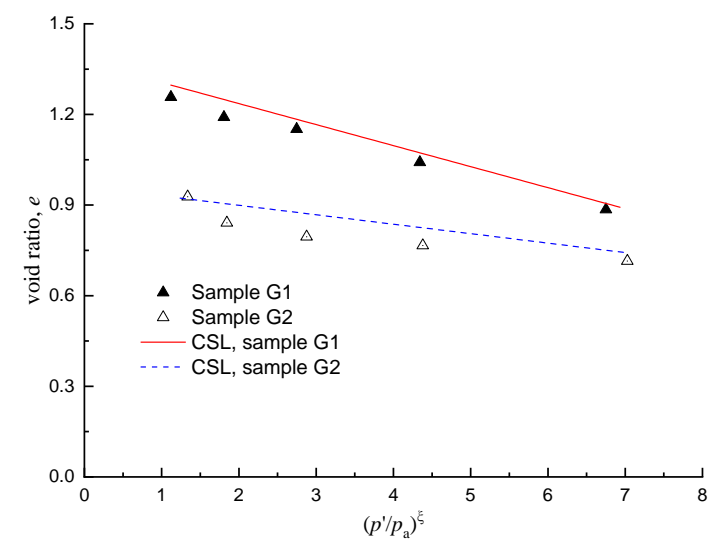

Fig. 6 Critical state line in e-(p'/pa) $)^{\xi}$ plane

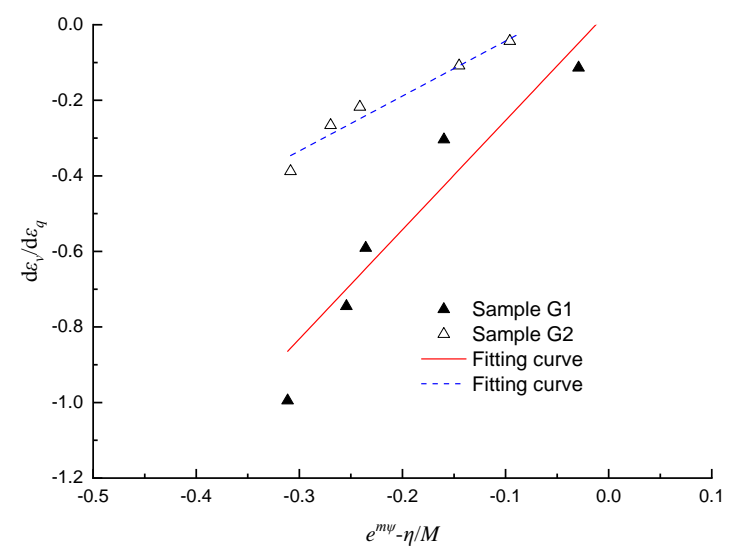

Fig. 7 Determination of parameter $\mathrm{d} 1$ from triaxial tests

According to Li and Dafalias (2000), ignoring the small elastic,

$$
\frac{d \varepsilon_{v}}{d \varepsilon_{q}} \approx \frac{d \varepsilon_{v}^{p}}{d \varepsilon_{q}^{p}}=d=d_{1}\left(e^{m \psi}-\eta / M\right)
$$

where $\varepsilon_{\mathrm{q}}$ is deviatoric strain and the superscript $p$ denotes plastic. The parameter $d_{1}$ can then be calibrated based on the $\varepsilon_{\mathrm{v}}-\varepsilon_{\mathrm{q}}$ curves. In order to evaluate the applicability of state-dependent dilatancy function to calcareous sand, the value of $d_{1}$ has been determined from drained triaxial compression test data. Fig. 8 presents the relationship between the maximum value of $\mathrm{d} \varepsilon_{\mathrm{v}} / \mathrm{d} \varepsilon_{\mathrm{q}}$ and the dilatancy parameter $\left(e^{m \psi}-\eta / M\right)$ correspond to the same state. It can be seen from Fig. 7 that for triaxial conditions the parameter $d_{1}$ can be regard as a constant independent of both density and confining pressure, but dependent on particle size and sample size. Table 2 lists out all the parameters used.

Table 2 Material parmeters in state-dependent dilatancy function

\begin{tabular}{cc}
\hline Sample G1 & Sample G2 \\
\hline & $M=1.621$ \\
\hline$e_{\Gamma}=1.375$ & $e_{\Gamma}=0.926$ \\
\hline$\lambda_{\mathrm{c}}=0.0696$ & $\lambda_{\mathrm{c}}=0.0103$ \\
\hline$m=-1.978$ & $m=2.674$ \\
\hline$d_{1}=2.892$ & $d_{1}=1.454$ \\
\hline
\end{tabular}

\section{CONCLUSIONS}

In order to analyze the influence of the particle size on the strength and deformation behaviors of calcareous sand, a series of triaxial compression tests were performed on the calcareous sand with maximum particle diameters of $2 \mathrm{~mm}$, and $20 \mathrm{~mm}$ at different density. Based on the results of the shear tests, the following conclusions could be drawn:

(1) Calcareous sand presents stress-strain soften behavior. Particle size has no obvious effect on the type of stress-strain relationship.

(2) Particle size had great influence on volume change of calcareous sand. The volumetric strain experiences contraction to dilatation with increasing of shear strain. The dilatancy tendency decrease with increasing of particle size and effective confining pressure. At the same stress state, samples with coarse grains have larger volume compression before dilatancy.

(3) Shear strength increase with particle size. Samples with different particle size have a unique critical state line in $p^{\prime}-q$ plane, but different critical state line in $\mathrm{e}-(\mathrm{p} / \mathrm{pa})^{\xi}$ plane.

\section{ACKNOWLEDGEMENTS}

The authors thank the National Natural Science Foundation of China (Grant No. 51639008) for the financial support.

\section{REFERENCES}

1) Been, K. G. and Jerreries, M. G. (1985): A state parameter for sands, Geotechnique, 35(2), 99-112.

2) Bolton, M. D. (1986): The strength and dilatancy of sands, Geotechnique, 36(1), 65-78.

3) Brandes, H. G. (2011): Simple shear behavior of calcareous and quartz sands, Geotech. Geol. Eng., 29, 113-126.

4) Coop, M. R. (1990): The mechanics of uncemented carbonate sands, Geotechnique, 40(4), 607-626. 
5) Datta, M., et al. (1980): Geotechnical properties, behaviour and performance of calcareous soils, Geotechnique, 80 (1), 217 222.

6) Duncan, J. M. and Chang, C.Y. (1970): Nonlinear analysis of stress andstrain in soils, J. Soil Mech. and Found. Div., 96(5), 1629-1653.

7) Dunn, S. and Bora, P. K. (1972): Shear strength of untreated road base aggregates measured by variable lateral pressure triaxial cell, Journal of Mechanics, 7(2), 131-142.

8) Islam, M. N., et al. (2011): Effect of particle size on the shear strength of sand, Australian Geomechanics, 46(3), 75-85.

9) Koerner, R. M. (1970): Effects of particle characteristics on soil strength, Journal of Soil Mech. and Found. Div., ASCE, 96(4), 1221-1234.

10) Li, X. S. and Wang, Y. (1998): Linear representation of steadystate line for sand. Journal of Geotechnical and Geoenvironmental Engineering, ASCE, 124(12), 1215-1217.

11) Li, X. S. and Dafalias, Y. F. (2000): Dilatancy for cohesionless soils, Geotechnique, 50(4), 449-460.

12) Qian, K., et al. (2017): Experimental study on permeability of calcareous sand for islands in the South China sea, Rock and Soil Mechanics, 38(6):1554-72. (In Chinese).

13) Shahnazari, H. and Rezvani, R. (2013): Effective parameters for the particle breakage of calcareous sands: an experimental study, Eng. Geol., 159 (12), 98-105.

14) Vangla, P. and Latha, G. M. (2015): Influence of particle size on the friction and interfacial shear strength of sands of similar morphology, Int. J. of Geosynth. and Ground Eng, 1-6.

15) Wang, J., et al. (2013): Effects of particle size distribution on shear strength of accumulation soil, Journal of Geotech. Geoenviron. Eng., 139(11), 1994-1997.

16) Wang, X. Z., et al. (2014): A new apparatus for testing the bearing capacity of calcareous sand in laboratory, Marine Georesources \& Geotechnology, 32(4), 379-386.

17) Wang, X. Z., et al. (2017): Study of permeability of calcareous silty layer of foundation at an artificial reclamation island, Rock and Soil Mechanics 38(11):3127-3135. (In Chinese).

18) Wang X., et al. (2019). Study of dilatancy behaviors of calcareous soils in a triaxial test, Marine Georesources \& Geotechnology, 37:9, 1057-1070.

19) Lv, Y., et al. (2019): Effects of particle size on dynamic constitutive relation and energy absorption of calcareous sand, Powder Technol.

20) Zhang, J. M., et al. (2009): Research on influences of particle breakage and dilatancy on shear strength of calcareous sands, Rock and Soil Mechanics, 30(7):2043-2048. (In Chinese).

21) Zhu, C. Q., et al. (2014): Microscopic characterization of intra-pore structures of calcareous sands, Rock and Soil Mechanics 35(7):1831-1836. (In Chinese). 